\title{
MEMÓRIA FUTURA, POESIA MADURA
}

\author{
Solange Fiuza C. YOKOZAWA ${ }^{90}$
}

FRANCHETTI, P. Memória futura. Cotia, SP: Ateliê, 2010. 64 p.

Há vantagens e desvantagens em se tornar um poeta édito na idade madura. Por haver passado o afã experimentalista dos verdes anos, quando se está ensaiando formas de expressão, descobrindo caminhos, o poeta maduro, normalmente, não oferece aquela palavra fundada na ruptura radical, que desconcerta o leitor e o obriga a rever seus paradigmas de beleza. Mas também o poeta que se dá a conhecer em plena maturidade, respeitoso com o seu amigo leitor, tende a privá-lo de suas hesitações criativas, titubeios e poses juvenis e lhe oferece uma palavra depurada em anos de labor. Entretanto, esta talvez seja uma atitude rara numa época em que se tornou relativamente fácil publicar um livro, em que parece extinto o pudor de se dar a conhecer ao público, em que jovens com um espírito crítico ainda não cultivado querem publicar mal domado o prurido dos primeiros versos, em que se experimenta uma sensação de que há mais pessoas que se creem poetas do que receptores para seus textos.

Memória futura (Ateliê, 2010), de Paulo Franchetti, pertence a essa safra escassa de livros amanhada por poetas líricos que já nascem maduros para o público.

Ainda que este seja seu primeiro livro de poesia estritamente lírica ${ }^{91}$, pelo menos no sentido em que o Ocidente concebe o gênero, Franchetti não é nome desconhecido para o leitor que procura se informar sobre as produções críticas voltadas às literaturas de língua portuguesa. Professor da UNICAMP, onde dirige a editora dessa casa acadêmica, Franchetti é crítico (re)conhecido que assina livros de frequência obrigatória para um profissional com interesse na área de estudos literários, como, entre

\footnotetext{
90 Professora da Faculdade de Letras da Universidade Federal de Goiás, Goiânia, GO, Brasil solfiuza@hotmail.com

${ }^{91}$ Depois que escrevi esta apresentação, tomei conhecimento de dois livros de poesia lírica de Franchetti: Várias vozes, que saiu pelo Centro de Estudos de Letras da Faculdade de Filosofia, Ciências e Letras de Araraquara, em 1975, e Indigo blues, publicado em Campinas, em 1984. Mesmo que o autor tenha aproveitado em Memória futura um poema do livro de 84 ("Na parede do quarto", p.21), ainda não se encontra, nesses poemas da juventude, o autor de Memória futura. De circulação bastante restrita, os poemas reunidos em uma publicação do centro acadêmico na época da faculdade e em um folheto mimeografado certamente tiveram seu papel no processo de formação do poeta, que se dá a conhecer no esplendor de sua madureza no livro de 2010.
} 
outros, Alguns aspectos da teoria da poesia concreta (UNICAMP, 1989), Nostalgia, exílio e melancolia - leituras de Camilo Pessanha (EDUSP, 2001) e Estudos de literatura brasileira e portuguesa (Ateliê, 2007), tendo organizado também uma edição crítica de Clepsydra (Relógio D’água, 1995) que faz verdadeiramente justiça à obra pequena e expressiva do simbolista português Camilo Pessanha. Ainda, é autor de numerosos artigos e capítulos de livros que trazem reflexões significativas sobre as literaturas brasileira e portuguesa, entre os quais vale destacar aqueles que têm ajudado a rever a recepção crítica machadiana e a limpá-la de algumas reduções ou equívocos. Certamente, o poeta lírico, que talvez tenha nascido antes e tenha sido mesmo o responsável por uma escolha profissional que dura uma vida inteira, foi se aperfeiçoando no cadinho do crítico.

Obra lírica de um crítico de projeção, Memória futura não é, entretanto, o primeiro trabalho especificamente criativo do autor. Em 2003, publicou a novela $O$ sangue dos dias transparentes; em 2007, o belíssimo Oeste, livro de haicais em edição bilíngue e, em 2009, a reunião de poesia fescenina Escarnho, que esteve entre os semifinalistas do prêmio Portugal Telecom 2010. Quem acompanha essas produções do autor talvez perceba o quanto delas está contido no novo livro, apesar das diferenças de gênero, ou o quanto do poeta de Memória futura já se encontra nessas obras anteriores.

Em Oeste $^{92}$, o haicai é atualizado não como sacada lírica ou irônica vazada em três versos, como frequentemente se observa em produções assim nomeadas no Brasil, mas como uma forma de ver o mundo, como registro de uma percepção exterior original, notadamente daquelas despertadas pela sucessão das estações do ano, pelo transcorrer do tempo, o que situa o autor numa linha de tradição que remonta diretamente a Bashô. Tradição que Franchetti conhece muito bem, sendo ele o responsável pela tradução, em parceria, de haicais de Bashô, Issa, Buson, entre outros, publicados no livro Haikai (UNICAMP, 1990). Também, é autor de um trabalho esclarecedor sobre a poesia clássica japonesa que serve de prefácio a esse livro.

O olhar do haicaísta continua presente em muitos poemas de Memória futura, nos quais, em lugar da subjetividade hegeliana que fundamentou majoritariamente por muito tempo a concepção de poesia lírica ocidental, tem-se aquele registro objetivo do

\footnotetext{
${ }^{92}$ Franchetti publicou, em 1994, uma coletânea de haicais, numa parceria de Massao Ohno e da Aliança Cultural Brasil-Japão. Oeste retoma esse primeiro livro, incorporando outros poemas escritos pelo autor ao longo dos 15 anos seguintes.
} 
mundo que Hegel notou na poesia oriental. Segundo Hegel (1997, p.546), nessa poesia (o pensador não considera os japoneses, mas suas reflexões são válidas para a poesia nipônica), a realidade exterior não é apenas o pretexto para que o eu se expresse. Nela, afirma-se não a interioridade do poeta recluso em si mesmo, mas a sua direção para os objetos e situações exteriores, o que confere um tom objetivo à poesia oriental, pois o poeta não exprime as coisas e as circunstâncias como as concebe, mas confere a elas uma vida independente. Não cabe aqui discutir os limites da dicotomia poesia objetiva $\mathrm{X}$ poesia subjetiva. Por ora, chamo a atenção para a permanência do olhar do haicaísta em vários poemas de Memória futura, dos quais transcrevo um dos quadros arrolados sob o título "Três":

2. Sobre a neblina, o sol

Espalha seu calor inútil.

Uma lata de leite, virada com o pé, Mostra a parte de dentro.

Ela quase brilha,

Atingida pela luz difusa. (p.12)

Coberto pela neblina, o sol continua a brilhar mesmo sem ser visto. A luz difusa que atravessa o nevoeiro atinge uma lata vazia, que, objeto sem serventia, foi jogada fora. "Ela quase brilha". Nesse poema, encontramos o mesmo amor e respeito às coisas ínfimas, o mesmo sentimento piedoso que subjazem a muitos haicais - e também a boa parte da poesia de lastro modernista - e leva o poeta a recolher a coisa considerada imprestável no espaço de um poema em que o eu aparentemente se apaga para evidenciar o objeto por ele iluminado.

Se o olhar contemplativo e piedoso do haicaísta não desaparece em Memória futura, tampouco a maturidade memorialista e reflexiva do novelista de $O$ sangue dos dias transparentes. Essa novela é constituída por capítulos rápidos e de corte irônico, que possuem autonomia como contos, mas, lidos no conjunto, compõem uma radiografia do homem urbano contemporâneo, com sua vida sem grandes acontecimentos épicos ou romanescos, mas feita daqueles pequenos lances vividos em carne, corpo e sangue: um encontro erótico casual e esplendoroso aqui, uma cena de separação acolá, a experiência mágica da infância, um amor da adolescência, enfim, 
tudo aquilo que, tendo escoado com os dias, permanece tocando as cordas da sensibilidade do narrador. É esse narrador que aparece criticamente nos textos de abertura e fechamento da novela, os quais servem de moldura aos capítulos-contos e a eles conferem coesão. É esse narrador que, maduro, qual aquele do último volume de Em busca do tempo perdido, procura recolher o sangue que se esvaiu com os dias. Mas lhe restam apenas a memória, feita de fragmentos e lacunas, e a língua, com sua força afetiva, para recuperar, entender e reinventar artisticamente o que se perdeu na carne das horas.

Essa mesma atitude memorialista e reflexiva subjaz a Memória futura, livro que, ao seu modo, também radiografa, mas em chave lírica, o homem contemporâneo. Ao se chegar ao final da leitura de Memória futura, tem-se a impressão de que a voz e a visão maduras aparecidas explicitamente nos últimos e belos e pungentes poemas comandam a tecedura inventiva das fibras de vida com que são fabricados os poemas do livro. Exemplar nesse sentido é o poema abaixo, que encena um procedimento que está na base da construção do livro:

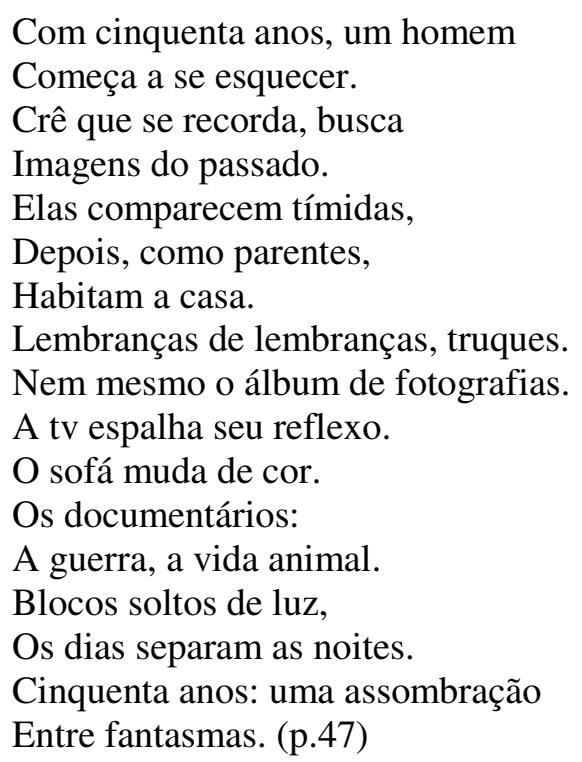

Essa atitude nada complacente para com a madureza que se lê nesse poema pode ser que acuse também a permanência, em Memória futura, da verve irônica que assinala as composições de Escarnho. Mas enquanto nesse livro de poesia fescenina a ironia está a serviço de uma sátira cruel vazada em estilo clássico e nutrida pela melhor tradição do gênero, em Memória futura a ironia tem como alvo o próprio sujeito lírico. 
Nesse caso, talvez fosse melhor falar em humor, já que existe um ponto de vista segundo o qual a ironia é o espírito à custa dos outros e o humor é o espírito à custa própria (Quintana, 1983, p.111). Assim como o poema abaixo que, tal qual o anterior, também diz o outono do corpo:

O tempo da velhice não amadurece.

$\mathrm{O}$ azedo persiste até que a fruta esteja podre.

O espelho é um animal doméstico que me aguarda.

Mas contra as vitrines não há defesa, nunca é hora de perdão.

Assim as fotos: feras de outro tempo, saltam sobre o dorso

[encurvado,

Rasgam as carnes da barriga, a pele acumulada no pescoço.

Restaria o olhar da mulher que envelhece comigo.

Caso o pudesse sustentar,

Conhecendo a distância do que me imagino

Ao que sou,

E daí ao que podemos, quando a noite cai. (p.41)

A perspectiva predominante nesse poema, como em outras composições da madureza de Memória futura, não é mais aquela objetiva, referida alhures, mas uma subjetividade hegeliana, ainda que desromantizada, escoimada de sentimentalismo. Assumindo essa perspectiva, o poema encara o tempo da velhice sem artifícios. O sujeito que envelhece se dá conta de que os problemas não se resolvem e as angústias não se serenam com o passar dos anos. O mau trabalho que a mão do tempo realiza sobre a aparência exterior lhe é revelado sem condescendência pelos objetos reflexivos (espelho, vitrinas) e pelas fotografias que, tiradas para reter o tempo, antes denunciam a sua passagem. O "animal doméstico" sempre à espreita não permite a ilusão consoladora que aparece em "Versos de natal", de Manuel Bandeira (1991, p.145), quando o eu-lírico enrugado, de olhos míopes e cansados, socorre-se no menino que o habita. Certeza alguma arrefece o peso dos anos para o homem que encara a velhice sem subterfúgios.

Nesse, como em outros poemas da madureza de Paulo Franchetti, não se encontra aquele apaziguamento de quem, diante do tempo que a tudo arrebata, sente sua vida mais plena daquilo que o tempo não pode levar, como se lê em poema bandeiriano da Lira dos cinquent'anos (BANDEIRA, 1991, p.150-151). Na lira dos cinquent'anos de Franchetti, a visão da madureza mais se aproxima daquela visada impiedosa de Drummond, também um quase quinquagenário quando da escrita e publicação de Claro 
enigma, onde aparecem versos como estes: "A madureza, essa terrível prenda/que alguém nos dá, raptando-nos, com ela,/todo sabor gratuito de oferenda" (Drummond, 1995, p.18). Mas a situação quotidiana, diria mesmo doméstica, em que o sujeito lírico de Memória futura evidencia a consciência do envelhecimento, confere aos poemas da madureza desse livro um tom mais tocante e patético do que o que se depreende dos versos drummondianos.

Ainda que esses poemas estejam entre os mais lancinantes e belos do livro, nem só da consciência da madureza vive o homem verdadeiramente maduro. Entre outras searas do livro e da memória, destaco o conjunto de poemas que está sob o signo de Eros. Com esse signo me refiro tanto aos poemas que dizem o erotismo dos corpos quanto àqueles que liricizam a mulher amada ou o amor de um modo geral. Limito-me a estes dois exemplos:

\section{LEDA}

(por um poema de Yeats)

Enquanto o bico corta a carne da nuca

E o sangue colore o fio da coluna,

Os rins se erguem numa entrega inerte

$\mathrm{E}$ as pernas se separam, já dormentes.

Seio contra as pernas, mal as membranas lhe tocam

A pele da barriga.

As grandes asas prefiguram num momento

A glória de Tróia e as tardes de outono sobre os campos e os [trigais

E de súbito se afastam,

Agitando as folhas do carvalho,

Enquanto ela dorme, lacerada e confundida,

As mãos inúteis jazendo sobre o chão. (p.26)

A mão dela apoiada sobre o peito dele.

Desce uma luz

Que parece do céu,

Mas é o flash refletido na vidraça.

O melhor de cada um

Dirigido à lente

E à memória futura da fotografia.

Toda a vida, depois,

O gosto amargo de não ter

O que, sem esforço e sem palavras,

Fizeram ser imagem. (p.17) 
Em "Leda", para dizer a cena de amor natural (quem sabe uma reinvenção em versos líricos do sexo casual do conto "Cabelo", de O sangue dos dias transparentes), o poeta recupera o mito de Zeus metamorfoseado em cisne para apossar-se de Leda. Sua fonte declarada e reverenciada é o mito como o atualizou poeticamente Yeats (2000, p.182) em uma das mais belas composições de todos os tempos: "Leda and the Swan". O encontro erótico de dois corpos reatualiza o mito. Em Yeats, um tremor dos quadris de Leda engendra a destruição de Tróia e a morte de Agamêmnon ("A shudder in the loins engenders there/The broken wall, the burning roof and tower/And Agamemnon dead'), já que Helena, a causadora da ruína da cidade, e Clitemnestra, que matou seu marido Agamêmnon depois de este voltar da guerra troiana, foram geradas nessa união fugaz e violenta. No poema de Franchetti, o encontro dos corpos representa de antemão o êxtase seguido da serenidade: "As grandes asas prefiguram num momento/a glória de Tróia e as tardes de outono sobre os campos e os trigais". O que glorificou epicamente a cidade de Príamo foi a guerra que a destruiu. Nos dois poemas, malgrado as diferenças, Eros e Tânatos, impulso de vida e destruição mortal subjazem ao gesto amoroso. Mas, no de Franchetti, a fratura irônica se insinua na liricização do ato amoroso, estabelecendo uma diferença crítica em relação ao soneto de Yeats. Enquanto os versos finais do soneto interrogam sobre a ciência e o poder que porventura Leda teria assumido na posse amorosa brutal ("Did she put on his knowledge with his power/Before the indifferent beak coud let her drop?"), a versão franchettiana explicita que, depois da posse física, nada resta de sublime ou transcendente para a mulher (ou para o homem), que jaz inerte sobre o chão. Para um poeta contemporâneo, talvez o sublime se deixe entrever apenas de relance no gesto fugaz e resplandecente do êxtase amoroso.

Outra rasteira irônica no sublime amoroso encontra-se no segundo poema transcrito, que começa com uma descrição precisa de uma fotografia de um casal. O eulírico que, no presente da enunciação, olha e descreve o retrato, vislumbra a transcendência numa luz insinuada na foto, "que parece do céu". Mas a transcendência é aparente e, portanto, vazia, pois se trata apenas do flash refletido na vidraça. O melhor do par amoroso está congelado no retrato, desejo do que poderia ter sido e do que, sabeo a consciência presente e dorida que manuseia "a memória futura da fotografia", não foi. 
Como nesse poema cujo verso dá título ao livro, toda memória só pode ser futura, muitas vezes dolorosamente futura. Nesse tempo que é futuro em relação ao pretérito e é o aqui-agora do poeta, resta apenas o gesto compreensivo e amoroso da palavra poética. Para guardar em poesia os fios que, mesmo precários, compõem uma vida. Para louvar ao Criador e a toda uma tradição poética, mesmo que de modo blasfemo e em chave irônica, como faz Franchetti em poema que cito para fechar esta apresentação, a qual dá apenas uma pequena amostra das "belezas maculadas" que Memória futura inventaria liricamente e cabe ao leitor descobrir:

BELEZA MACULADA

(por um poema de Hopkins)

Glória ao Criador pelas coisas machucadas, Pelas veias partidas nos casais de ocasião, Pela mancha rosa, toda pontilhada De pequeninos sulcos, chagas em botão Pelo vago rubro vergão na carne clara, Pela unha que arranha a coxa fugitiva Um peixe a debater-se sob anáguas. Pela pele rompida, logo remendada, E por toda ferida de amor, Incendiada e acariciada.

Todas as coisas em excesso, vulgares, interditas (Sangue doce, restos de saliva, Dobras nítidas do ventre envelhecido), Quem produziu isso tudo foi Aquele Cuja beleza é imutável: Que a glória seja d'Ele! (p.40).

\section{REFERÊNCIAS}

ANDRADE, C. D. de. Claro enigma. 11.ed. Rio de Janeiro: Record, 1995.

BANDEIRA, M. Estrela da vida inteira. 19.ed. Rio de Janeiro: J. Olympio, 1991.

FRANCHETTI, P. Escarnho. Cotia, SP: Ateliê, 2009.

Oeste. Cotia, SP: Ateliê, 2007.

O sangue dos dias transparentes. Cotia, SP: Ateliê, 2002.

HEGEL, G.W.F. II. A poesia lírica. In: Curso de estética: o sistema das artes. Trad. Álvaro Ribeiro. São Paulo: Martins Fontes, 1997. p.510-555.

QUINTANA, M. A vaca e o hipogrifo. 4.ed. Porto Alegre: L\&PM, 1983. 
YEATS, W.B. The collected poems. London: Wordsworth, 2000. 